\title{
ESTIMATIVA RÁPIDA DE CÁRIE EM CRIANÇAS DE TRÊS ANOS RESIDENTES EM CAMBÉ-PR
}

Adrieli BUREY, Lucimar Aparecida Britto CODATO, Maria Celeste MORITA, Maura Sassahara HIGASI, Maria Luiza Hiromi Iwakura KASAI

O serviço municipal de saúde de Cambé-PR ainda não havia realizado estudo para verificar a presença ou não da doença cárie dentária em crianças de três anos de idade matriculadas em instituições municipais. Este estudo foi realizado em parceria com a Universidade Estadual de Londrina e concluído em 2009. Foram examinadas 137 crianças, de ambos os sexos, para verificar a presença ou não de lesões cariosas de universo de 151 crianças matriculadas nos Centros Municipais de Educação Infantil. A pesquisa recebeu parecer favorável pelo Comitê de Ética em Pesquisa da Universidade Estadual de Londrina-PR. Os profissionais envolvidos no processo foram treinados e calibrados para atuarem como examinadores para assegurar interpretação uniforme e consistente de critérios diagnósticos. Verificou-se que 84,67\% dessa população estudada não tinha experiência da doença cárie dentária. A região norte do município apresentou a menor percentagem de crianças livres de cárie $(76,92)$ e a região central o maior percentual de crianças livres de cárie $(91,80)$. Neste estudo, apesar da alta percentagem de crianças livres de cárie, constatou-se diferenças regionais que sugerem a necessidade de avaliação e planejamento visando à implementação de ações multiprofissionais e intersetoriais.

Palavras-chave: Cárie dentária; Epidemiologia; Saúde bucal. 